\title{
DILEMAS DE LA EDUCACIÓN PATRIÓTICA Y LA COHESIÓN SOCIAL. ARGENTINA, COMIENZOS DEL SIGLO XX
}

\author{
DILEMAS OF PATRIOTIC EDUCATION \\ AND SOCIAL COHESION. ARGENTINA, \\ BEGINNING OF THE XX CENTURY
}

\author{
RICARDO GONZÁLEZ LEANDRI • \\ Investigador del Centro de Ciencias Humanas y Sociales, \\ Consejo Superior de Investigaciones Científicas (España). \\ E-mail: rgleandri@gmail.com
}

\section{Resumen}

Este artículo analiza las narrativas de cohesión social que cristalizaron en la primera década del siglo XX en Argentina. Se centra en particular en el impulso sistemático a una educación patriótica en las escuelas, un experimento que implicó diferencias e incluso choques entre distintas maneras de concebir la acción social y cultural. Lo más destacado de tal proceso fue que, a pesar de sus diferencias, casi todos sus participantes consideraban prioritario alcanzar un nuevo pacto de solidaridad que ayudara a redefinir los vínculos sociales existentes.

\section{Registro bibliográfico}

GONZÁLEZ LEANDRI, RICARDO «Dilemas de la educación patriótica y la cohesión social. Argentina, comienzos del siglo XX», en: ESTUDIOS SOCIALES, revista universitaria semestral, año XXIX, $n^{\circ} 57$, Santa Fe, Argentina, Universidad Nacional del Litoral, julio-diciembre, 2019, pp. 137-159.

\section{Abstract}

This paper analyses the narratives on social cohesion that crystallized during the first decade of the twentieth century in Argentina. It specifically focuses on the systematic promotion of a patriotic education at schools, an experiment which implied disagreements and even clashes amongst the different views and ways of conceiving social and cultural action. The most outstanding aspect of the process was that despite the differences, almost all the participants considered a priority to reach a new solidarity pact that would help to redefine the existing social links.

\section{Descriptores · Describers}

Argentina / Cohesión social / Educación / Educación patriótica / Solidaridad

Argentina / Social cohesión / Education / Patriotic education / Solidarity

Recibido: 30 / 01 / 2018 Aprobado: 15/08/2018 


\section{INTRODUCCIÓN}

En este trabajo estudiamos las narrativas de cohesión social y homogeneidad cultural asumidas por intelectuales y funcionarios que cumplieron distintos roles en la promoción de educación patriótica en las escuelas públicas argentinas a partir de 1907, cuando desde el Ministerio y el Consejo Nacional de Educación se dictó una serie de normativas específicas al respecto ${ }^{1}$.

El campo educativo es un ámbito privilegiado para observar la complejidad y tensiones a las que han sido sometidas en determinados momentos históricos tanto la acción como las reflexiones sobre el sentido del vínculo social, sus cadenas de solidaridad e interdependencia y, también, las amenazas a las que se creía que el mismo estaba expuesto (DE SWAN, I992; MULLER, RINGER Y SIMON, I992; GELLNER, I983; CRIADO, 2OIO). Situamos la indagación en un marco histórico que presupone la construcción de un espacio de lo social — dependiente pero a su vez diferenciado de los grandes campos del mercado y de la política- que facilitó el afianzamiento temprano de procesos de regulación pública (DONZELOT, I994; GONZÁLEZ LEANDRI, GONZÁLEZ BERNALDO Y SURIANO, 2OIO; GONZÁLEZ LEANDRI, GONZÁleZ BERNALdo y galera gómeZ, 20I5). Apelamos para esto al concepto sociológico de cohesión social, atendiendo a los enfoques que promueven su redefinición en términos históricos a partir de una vuelta a su sentido durkheimiano original de "pegamento social» y solidaridad (DURKHEIM, 2004; TIRONI Y SORJ, 2007; BARBA SOLANO, 2OII).

Con este objetivo nos proponemos abordar en el campo educativo de la primera década del siglo xx una serie de temas en tensión con los que dicho concepto se solapa, como las ideas de homogeneidad, integración, solidaridad, igualdad/ desigualdad y sociabilidad. Esto implica desplazar el foco de análisis desde la cuestión social —entendida en términos de moderno conflicto social— hacia el de la emergencia de narrativas sobre un «nosotros» colectivo y sus interrelaciones con el mundo social.

1] Este artículo es uno de los resultados del proyecto «Formas y representaciones de la cohesión social. Una perspectiva histórica a partir de experiencias de sociabilidad sudamericanas, 1870-1960» HAR 201565564, financiado por el Ministerio de Economía y Competitividad del gobierno de España. Agradezco los comentarios de mis compañeros de proyecto y las sugerencias de Carola Aikin y Susana Terracini. 


\section{COHESIÓN SOCIAL Y CONFIGURACIONES EDUCATIVAS EN EL SIGLO XIX}

A lo largo del siglo xix, la noción de cohesión social, que implica pensar la sociedad como un todo, apareció bajo variadas formas a partir de configuraciones político-institucionales diferentes. En la década de I850, con la caída de Rosas y el empuje constitucional; en los años 80, con la consolidación estatal; y en los '9o con la crisis política e institucional, entre otras. En esas coyunturas se reactualizó la preocupación por el sentido del vínculo social y por sus condicionantes específicos, presentes desde los tiempos de la modernidad ilustrada (GONZÁLEZ BERNALDo, 2OI8; HALPERIN DONGHI, I980; GALLO Y BOTANA, I997; ZIMMERMAN, I994).

Por su papel en el impulso a la reproducción cultural, resulta evidente la ligazón entre las iniciativas emanadas del dispositivo educativo, en la época un conjunto poco articulado de iniciativas de actores de procedencia diversa, con las narrativas vigentes que implicaron a la cohesión social: civilización y barbarie, poblar el desierto, educar al soberano, orden y progreso, entre otras. Esta perspectiva se ve reforzada por el hecho de que a los trabajos ya clásicos, que han abundado en el sentido eminentemente político de la educación durante el siglo XIX, se han ido agregando otras interpretaciones que dan cuenta de la riqueza de sus dimensiones múltiples y de su ligazón con el mundo de lo social y con la construcción estatal (TEDESCO, I986; MARENGO, I99I; DUSSEL, I995; PINEAU, I997; FIORUCCI, 2004; LIONETTI, 2007; FINOCCHIO, 2009; LEGARRALDE, 2008; RODRÍGUEZ, 2OI8).

Dado que este artículo se orienta a detectar narrativas de cohesión social consolidadas entre los últimos ańos del siglo xIx y comienzos del xx, conviene señalar algunas cuestiones básicas que actúan como antecedentes insoslayables. El sistema público de educación elemental inició un proceso de afianzamiento en la década de i88o. Con la cuestión del orden nacional resuelto, se señala como hecho fundacional la promulgación en I884 de la Ley 1420 de Educación Común, que estableció la educación elemental obligatoria laica y gratuita para los niños entre los 6 y los I4 años. Sin embargo, la significación de este hecho, que algunos autores han observado como un rasgo de estatidad, no oscurece la relevancia de cuestiones promovidas con anterioridad en distintos ámbitos, como el afianzamiento de corrientes pedagógicas laicistas, los esfuerzos municipales por equilibrar el trato a ricos y pobres, la promoción de escuelas mixtas y la participación ciudadana en la dirección de las escuelas (ZUCHMAN, 1986; PINEAU, I997; GONZÁLEZ BERNALDO Y GONZÁLEZ LEANDRI, 20I5). La impronta de estas cuestiones, con las figuras de Sarmiento y Manso y las ideas de educación del pueblo como estandartes, tiñó 
con efectos perdurables, a veces contradictorios, muchas de las iniciativas públicas en este campo (LIONETTI, 2007; FINOCCHIO, 2009). Las ideas de prevención y proyección a futuro derivadas de ese temprano empuje educativo se expandieron con posterioridad a otros espacios, como la salud y el trabajo. Gracias a ellas, la educación ayudó como casi ninguna otra área de la época a la constitución de lo social como campo de regulación pública.

La forma que adoptó finalmente la ley I420 fue el resultado de la pugna entre tres modelos alternativos de dirimir la relación entre el Estado, el sistema educativo y la cohesión social: el impulsado por el gobierno e intelectuales liberales que planteaban una decisiva intervención estatal; el de la Iglesia Católica que, sin negar la necesaria intervención del Estado, solicitaba mayores márgenes de autonomía para su proyecto; y el de las asociaciones populares de educación, que abogaban por su independencia dentro de unos marcos más flexibles pero también más imprecisos. Triunfó con comodidad la primera opción, pero por lo bajo, a lo largo del resto del siglo, las colaboraciones y desencuentros entre estas tendencias alternativas se reactualizaron en forma permanente.

Varias cuestiones encadenadas participaron del solapamiento entre educación y el campo de lo social en construcción. En primer lugar, la magnitud del esfuerzo por lograr una alfabetización masiva. Se trató de un proceso institucional pero igualmente de una pugna cultural en los que afloraron condicionamientos sociales, derivados de la situación socioeconómica de los sectores populares y las inquietudes de vecindarios y docentes. Sin embargo, si bien el efecto cohesionador de tal esfuerzo es innegable también lo es que sus objetivos se cumplieron solo en parte y de forma irregular

Lo mismo sucedió con la proclamada impronta estatal. La creación en I88Ide un Consejo Nacional de Educación con un declarado afán centralizador, aunque en principio con atribuciones solo en la Capital Federal y los territorios nacionales, fue un hito. Lo fue sobre todo por el hecho simbólico de colocar a intelectuales de primera línea a su frente, por su dotación económica (9,I2 \% del presupuesto anual del Estado), por el tipo de subvenciones ideado para canalizar los recursos y por la misión fiscalizadora de un recién creado cuerpo de inspectores (MARENGO, I99I; LEGARRALDE, 2008). Su permanente interacción con gobiernos provinciales y vecindarios, que continuaron asumiendo responsabilidades educativas fundamentales, generaron importantes debates centrados en la disyuntiva entre un gobierno educativo estatal y las bondades de uno societal, con arraigo en la tradición docente 
pero de compleja ejecución. Fueron promovidos sobre todo por los inspectores a través de críticas a los manejos clientelares de los gobiernos provinciales y por la falta de consenso con respecto a cuál era su relación deseada con los consejos escolares de distrito, órganos básicos de la participación vecinal en la educación.

La meta más ambiciosa del dispositivo educativo fue la imposición de un ideario civilizatorio de rasgos múltiples, entre los que destacó su afán moralizador (LIONETTI, 2007). La consolidación de esa moralización cívica que fue compartida con otros países de América Latina implicó, en palabras de Silvia Finochio, que «la educación inventa lo social como civilizatorio». Esto presuponía alcanzar cotas adecuadas de formación y estandarización entre los diversos niveles docentes a partir de la consolidación de un aparato de saberes científicamente legitimado (FINOCCHIO, 20I5).

La creación de la Escuela de Paraná fue un primer paso. A través de ella, la llamada elite normalista, heredera del ideario misional sarmientino y de la pragmática educación norteamericana, alcanzó a ocupar el centro de gravedad del sistema educativo, pero lo hizo dentro de unos marcos más rígidos y centralizados del que habían previsto sus primeros impulsores. Guiados por un ideal positivista no homogéneo, sus esfuerzos por alcanzar el monopolio de la práctica pedagógica y construir socialmente la docencia fueron intensos y dotaron al sistema de rasgos jerárquicos que afectaron de una manera peculiar la visión cohesionadora que pretendía impulsar (DUSSEL, I997).

Bajo la sombra protectora del Estado, los grupos mencionados entraron en una densa interacción. Cruzándose y diferenciándose, definieron una relación que se convertiría en una típica característica del sistema. Dicho vínculo actuó como tamiz de todo tipo de iniciativas, desde el impulso a la educación patriótica, la elección de textos escolares, la modificación de planes de estudio, hasta la creación de bibliotecas y el diseño de escuelas.

Otras cuestiones dan cuenta de la pluralidad de miradas implícitas en el dispositivo educativo de la época y tuvieron efectos cruciales sobre su impulso a la cohesión social. En primer lugar, el creciente protagonismo que hacia fin de siglo comenzaron a adquirir grupos subordinados a partir, por un lado, del afianzamiento de una narrativa que precisó con más detalle el papel de la infancia como sujeto social y, por otro, de la consolidación de la escuela como espacio con mayor grado de autonomía (CARLI, 2005; FINOCCHIO, 2009). Ambas cuestiones abrieron espacios de ascenso social y se vieron teñidas por la feminización de la profesión 
docente, sobre todo en los escalones más bajos, fundamental por todo lo que significó como elemento ideológico de promoción de solidaridades en distintos niveles: el Estado, el vecindario y la familia (MORGADE, I992; YANNOULAS, I996).

El gran objetivo civilizatorio de la educación decimonónica, entroncado con una visión optimista sobre el papel modernizador de los contingentes migratorios propia de la generación intelectual de 1937, vio surgir a su lado interpretaciones más pesimistas que hicieron visibles algunas preocupaciones con respecto a las consecuencias sociales de la migración realmente existente y priorizaron un reforzamiento más perentorio de códigos, sociabilidades comunes y homogeneidad cultural entre la población. La relación entre ambos idearios sufrió alteraciones a lo largo del siglo, lo que en el terreno de la acción indujo a distintos actores educativos a evaluar las iniciativas de las colectividades extranjeras y a veces a intervenir sobre ellas. Aunque las visiones críticas y pesimistas no alcanzaron a detentar la hegemonía que muchas veces se les presupone hacia fines de siglo, también es cierto que el propio Sarmiento, ya en Educación Común, obra publicada en I849, planteaba algunas prevenciones con respecto a posibles efectos no deseados del proceso que se avecinaba (SARMIENTO, I849). A pesar de resultar clave la cuestión inmigratoria, no fue el único tema que influyó en la relación entre los dos idearios de cohesión social mencionados. En especial, a partir de la creación del Consejo Nacional de Educación, la tarea de los inspectores fue dejando rastros indelebles a través de sus informes. Más allá de ayudar a generalizar y articular el sistema educativo, estos contribuyeron desde la práctica concreta a consolidar narrativas sobre otros temas, como la capacidad real del Estado, las limitaciones de su acción ideológica, la cuestión indígena y los dilemas educativos en zonas de frontera. Todas ellas introdujeron variantes sensibles en las formas vigentes de promoción a la cohesión social a través del sistema educativo.

\section{COSMOPOLITISMO, CUESTIÓN SOCIAL Y EDUCACIÓN PATRIÓTICA}

La crisis política y económica de los años I89o marcó un punto de inflexión en la sociedad argentina. A partir de esos años, las narrativas de cohesión social estuvieron determinadas por el conflicto social entre capital y trabajo y la irrupción social y política de sectores medios. Estos problemas alertaron a las elites dominantes y al gobierno, que tendieron a interpretarlos como parte integrante de un desafío más 
amplio a los fundamentos del orden político, económico y social (ZIMMERMAN, I994; BOTANA Y GALLO, I997; SURIANO, 2000). Inducidos también por la creciente división entre los elencos gobernantes tradicionales, comenzó a desplegarse una serie de críticas cada vez más frecuentes que consideraban que el notable crecimiento económico de las últimas décadas del siglo XIX no había sido lineal y que las expectativas de progreso, que se pensaba indefinido, debían ser matizadas.

La década de 1890 fue asimismo una época de cambios importantes y de proyectos institucionales. Uno de los más notables fue la mayor autonomía que adquirieron determinadas agencias estatales frente al mundo de la política, lo que permitió el afianzamiento de una intelligentsia técnica, evidente en los campos de la política sanitaria, la reforma urbana y la educación (GORELIK, 2OOI; BOHOSLAVSKY Y SOPRANO, 2OIO; RODRÍGUEZ Y SOPRANO, 2OI8). Esto indujo a varios autores a hablar de la consolidación de un poder normalizador en este último, con los inspectores como agentes encargados de garantizar primero el papel civilizatorio de la escuela y, posteriormente, su incumbencia patriótica (MARENGO, I99I; GAGLIANO, I99I; FANLO, 2007; LIONETTI, 2007). En otros niveles del dispositivo educativo se produjo un llamativo florecimiento de asociaciones y otras agrupaciones docentes, que produjeron una efervescencia de iniciativas y debates pedagógicos (FINOCCHIO, 2009 y 20I5; ALLIAUD, 2007; ACRI, 20I2). Esta situación convivió de manera tensa con el afán regularizador del aparato estatal, cuyo resultado más notorio fue la promulgación de la Ley Láinez en 1905. No es de extrañar que la década de I890 haya asistido a una vorágine de planes de reforma educativa. Derivadas de su elaboración, se escucharon con asiduidad voces críticas en cuanto a la trayectoria y papel social de la escuela. Puntualizaban que, tal cual venía funcionando, alimentaba fantasías democratizadoras desmedidas entre el alumnado y los propios docentes. A estos últimos se les achacaba su excesiva politización y su falta de formación, a la vez que advertían sobre los efectos negativos de su marcada feminización (MORGADE, I992; LIONETTI, 2007; FIORUCCI, 20I6).

En ese contexto surgieron iniciativas institucionales que promovieron el fortalecimiento de un «nosotros» colectivo, entre ellas, la que pretendía acelerar el impulso a la educación patriótica, que en realidad había comenzado de una manera un tanto dispersa varios años antes (ESCUDÉ, I990; CIAFFARDO, I99I; BERTONI, 20OI). El trasfondo de la cuestión para intelectuales y funcionarios involucrados en ella derivaba del clima de conflicto social, ruptura de los lazos tradicionales de sociabilidad y mercantilismo creciente, que veían en la Argentina de fines de siglo y que 
se resumía en una palabra: cosmopolitismo (RAMOS MEJÍA, [I9O0] I952; SOLBERG, I970; TERÁN, 2000; BERTONI, 200I; DEVOTO, 2002). Sintetizaba en su superficie los problemas originados por los efectos no deseados de la inmigración masiva y, en algunos casos, también las consecuencias de una modernidad desbocada. En un nivel más profundo, su utilización implicaba resaltar en forma complementaria la propia debilidad de la cultura local «nacional» y su falta de proyectos cohesivos. La popularidad del término fue innegable y su uso se convirtió en común. Para llegar a este punto, la idea de cosmopolitismo tuvo que pasar por un importante proceso de redefinición en el imaginario de las elites, al que no fueron ajenas las corrientes que veían en la degeneración uno de los males fundamentales del mundo moderno. De ser una fuente de incorporación de valores democráticos y de cualidades para la construcción de una nación moderna, con el tiempo, para muchos miembros de las elites, el inmigrante pasó a convertirse en un agente de disolución. ¿¿Pero de disolución de qué? Sagazmente, Jeane Delaney sostiene que a lo largo de esos años no fueron tanto las miradas sobre el inmigrante las que cambiaron sino las ideas subyacentes sobre lo que la Nación era y qué la unía (DELANEY, 1997). Incluso fervientes positivistas como Bunge comenzaron en el fin de siglo a desplazar cuestiones vinculadas a la voluntad política de pertenencia por factores culturales como, por ejemplo, el lenguaje o cierta fidelidad a un pasado común (TERÁN, 2000). A medida que la modernidad complejizaba las relaciones sociales y el conflicto social arreciaba, la Nación pasaba a ser considerada cada vez más como un núcleo espiritual, consecuencia de cierta homogeneidad racial o cultural preexistente. Esta visión étnico-cultural, que oscilaba entre cierto afán modernizador y el deseo de alcanzar una sociedad integrada y jerárquica, se fue haciendo un hueco frente a aquella otra, hegemónica hasta entonces.

La educación patriótica pretendía promover sentimientos de amor y veneración a la patria y sus héroes para intensificar un espíritu de nacionalidad que se consideraba escaso entre el estudiantado y la población en general. Partía, como se ha señalado, del diagnóstico de que la población se encontraba lastrada por el cosmopolitismo. La normativa que de ella se derivó se centró en cuestiones curriculares, como la enseńanza de historia y geografía y lengua nacional, pero, fundamentalmente, en una detallada sistematización de aspectos rituales, vinculados a la enseñanza en el aula y a conmemoraciones que implicaban a docentes, familias y vecindarios (ESCUDÉ, I990; GAGLIANO, I99I; BERTONI, 20OI; DEVOTO, 2002; LIONETTI, 2007; BRYCE Y SCHENIN, 2017). Según algunos participantes en 
el proceso, la pretensión era sobre todo redefinir y reencauzar formas vigentes de solidaridad que se consideraban poco funcionales a los propósitos modernizadores y aglutinadores de sus elites promotoras. Su aplicación fue, sin embargo, problemática. La división interna de la elite, tanto en términos políticos como intelectuales, sus tradicionales maneras eclécticas y la heterogeneidad del dispositivo que debía impulsarla, convirtieron a la educación patriótica en la primera década del siglo en un campo de experimentación donde lo étnico-cultural, lo social y lo político se entrecruzaron, a veces de forma paradójica.

Es evidente que los temas propios de la educación patriótica, por su vínculo con lo simbólico y ceremonial, y en especial por la estridencia de sus cultores, adquirió una presencia significativa. Sin embargo, es necesario matizar debido a que a veces el énfasis que revistas como El Monitor colocaron en la cuestión de la patria ha conducido a muchos autores a sobredimensionarla y a incurrir en anacronismos. Lo cierto es que los discursos alusivos a los sentimientos patrióticos convivieron con otros que mostraron una variada gama de matices en relación con el sentido que debía adquirir su impulso, que nadie negaba.

Para adentrarnos en los intersticios del impulso a la educación patriótica y observarla más como un espacio de experimentación que como uno de imposición efectiva, nada mejor que recorrer las páginas de El Monitor de la Educación Común, que a comienzos del siglo xx se convirtió en un auténtico termómetro de la cultura de la época. Dicha revista, creada por Sarmiento en los años I88o, cambió a comienzos de siglo parte de su sentido de correa de transmisión de la actuación oficial hasta convertirse en un foro de opinión que otorgó voz a distintos sectores del campo docente (FINOCHIO, 2009; FIORUCCI, 2OI4; DUARTE, 2OI4). La participación en la revista de intelectuales de renombre le dio un importante papel también a nivel doctrinario. Junto a ellos se hizo notar una serie de funcionarios de distinto rango. La frontera entre unos y otros era sumamente lábil y escenificó tensiones inherentes a la constitución del campo educativo. Participaron igualmente otros grupos, maestros, directoras de escuela y asociaciones docentes, cuyos ecos no se limitaron solo a hacer circular discursos emanados de otras esferas.

$\mathrm{Al}$ referirnos a los intelectuales, se debe tener en cuenta que, aunque alejado de las páginas de El Monitor, José María Ramos Mejía fue el gran operador institucional de la educación patriótica desde la década de 1900, a partir de la cual encaró la sistematización de iniciativas ya existentes. Su trayectoria lo muestra como una persona que fue paulatinamente desarrollando un ideario imposible de 
definir como nacionalista en un sentido clásico, pero sí sensible a resaltar en forma minuciosa aspectos donde la nacionalidad se imponía. Su muerte temprana impide evaluar su posible evolución, pero fragmentos de ensayos que dejó inconclusos permiten vislumbrar una deriva hacia una concepción bastante más esencialista y jerárquica de la nacionalidad que la expresada una década antes en Las multitudes argentinas. En esta obra, y sobre todo en Los simuladores de talento, alertaba sobre los peligros de los efectos no deseados de la inmigración masiva, que eran el cosmopolitismo y su consecuente materialismo, la fauna de la miseria y el «burgués aurius», representante de las inquietudes ascendentes y amenazadoras de las nuevas clases medias de origen inmigratorio (RAMOS MEJÍA, I9O0 y 1904). De todas formas, su pesimismo no le impidió confiar en las posibilidades de encauzamiento de las nuevas generaciones, los hijos de los inmigrantes, con capacidad de convertirse en el eje de un nuevo tipo de nacionalidad emergente (TERÁN, 2000).

La impronta personal impuesta por Ramos Mejía a la política del Consejo se hizo evidente en las páginas de El Monitor a través de la mayor participación que adquirieron algunos intelectuales que venían bregando desde hacía tiempo por el fomento de una educación patriótica. En agosto y octubre de 1908, a poco de asumir Ramos Mejía el cargo, Carlos Octavio Bunge publicó dos artículos notables «La educación patriótica ante la Sociología» y «Bosquejo histórico de la enseñanza nacional», que fueron representativos de la perplejidad de sectores de la elite frente a la migración y sus consecuencias (BUNGE, I908a y I908b). Si bien Ramos Mejía fue el operador institucional del empuje a la educación patriótica en este período, Bunge fue en realidad el ideólogo. De hecho, su actividad ya era muy notoria ańos antes, en los que publicó varios libros e informes sobre educación, uno de ellos editado en España con prólogo de Unamuno y una importante obra de referencia que fue Nuestra América (BUNGe, 1903 y 1905).

En dichos artículos argumentó en el sentido de reencauzar algunas de las manifestaciones sociales más evidentes del comienzo del siglo xx hacia nuevos sentidos en los que primaban maneras francamente jerárquicas de considerar el vínculo social. Según Bunge, dos cuestiones relacionadas convertían a la educación patriótica en un remedio necesario: las aspiraciones desmedidas de muchos inmigrantes que reactualizaban pugnas ideológicas de larga data y generaban malentendidos y tensiones sociales y el auge de erróneas y peligrosas ilusiones de igualdad. Se trataba para él de nociones y esquemas ideológicos que una correcta aplicación de los saberes científicos recientes podía ayudar a combatir. 
Sin abjurar de un biologismo positivista muy propio, Bunge enfatizaba la idea de que la sociedad era producto de los sentimientos sociales (TERÁN, 2000; FANLO, 2007). Dado que una de las funciones básicas del Estado era cultivar tales sentimientos, la educación impulsada por los gobiernos debía ser ante todo patriótica. El proyecto de promover tal tipo de educación tuvo para Bunge dos objetivos básicos: paliar los males acarreados por la anarquía intelectual propia de las corrientes democráticas e individualistas del siglo xix y, en particular, los provocados por la engañosa idea igualitaria orientada por el cristianismo. El destino era para él inevitable: al primar la desigualdad, los pueblos inferiores terminaban desapareciendo. En este punto, sus argumentos entran en tensión con respecto al tema inmigratorio. ¿Eran los deseados inmigrantes seres inferiores? ¿Cuál era el sentido cultural de la invasión cosmopolita? Misión de la educación patriótica era, para Bunge, ofrecer un marco institucional e ideológico adecuado para canalizar de manera coherente y poco conflictiva aquellas situaciones.

Efectivamente, la tensión argumental que se le presentaba al abordar la cuestión inmigratoria no tenía fácil solución para Bunge, algo muy evidente en las omisiones de su Bosquejo histórico de la educación nacional. Según se desprende de sus obras previas, el tema de la igualdad/desigualdad, situado en el centro de su análisis, tenía para él dos ejes, la cuestión indígena en la colonia y la cuestión inmigratoria en la época independiente. Sin embargo, ambos temas fueron tratados de manera desigual. Los argumentos utilizados para describir los problemas de la cuestión colonial, en especial los de la educación indígena, fueron muy precisos. El trasfondo ideológico es claro: nos dice Bunge: «Es hermoso creer en la igualdad y practicarla como lo tengo dicho en mi libro La Educación, pero la historia demuestra que los pueblos inferiores que se conquistan o se funden con los invasores o desaparecen» (I908b: 450-45I). En cambio, en los apartados dedicados al siglo xix el estudio se torna más superficial al mostrarse tributario de un enfoque institucional progresivo. Su rastreo de la formación de un carácter criollo, cuyos rasgos más característicos eran su brillante capacidad de asimilación y su pasión por el progreso, condujo a que la cuestión inmigratoria fuera objeto de una sintomática omisión. Centrales para su esquema, que relacionaba educación patriótica con igualdad/desigualdad, las acciones e influencia de los inmigrantes, tanto en términos positivos como negativos, se mantuvieron ocultas en el texto, que ensalzaba la «brillante capacidad de asimilación del pueblo criollo» (BUNGE, 1908b: 460). Ese silencio es expresión de una tensión ineludible. Al igual que en Ramos, la idea de país nuevo permitió 
a Bunge saltarse las consecuencias de decadencia social que los autores europeos en los que se orientaba veían como inevitables para su continente. Dada esa ambivalencia, ¿para qué tanto énfasis en promover la educación patriótica? Más que en cohesionar social y culturalmente a la población, su esquema estaba colocado al servicio del mantenimiento de la primacía de una visión jerárquica de la sociedad. Ya hemos señalado cómo durante esos años proliferaron opiniones que consideraban que la escuela pública ponía en riesgo el orden social por su politización y sus desbordes engañosamente democráticos. Resulta evidente que la proclama de Bunge ofrecía insumos importantes para su redefinición en la línea sugerida por esos sectores críticos (LIONETTI, 2007).

Otra interpretación destacada sobre los vínculos entre educación y búsqueda de homogeneidad social y cultural publicada en El Monitor durante estos años fue la de Leopoldo Lugones. No se trataba aún del intelectual de renombre en que se convertiría años más tarde sino de un joven y meticuloso funcionario con importantes condiciones. No es de un tema menor dado que esa tensión, producto del sentimiento de ser poco reconocido, impregnó su trayectoria (ECHEVERRía, 20IO: II-4I). Didáctica, un extenso ensayo publicado en capítulos a lo largo de distintos números de la revista, representó un serio y amplio programa de reformulación docente que abarcó múltiples planos. En realidad, fue bastante más que eso, puesto que implicó una profunda, brillante y contradictoria reflexión sobre el sentido de la sociabilidad y los vínculos sociales (LUGONES, I908: 589-597; 1909a: 216-233; 1909b: 36-49; 1909c: 417-445).

La idea central del trabajo giró alrededor de la necesidad de producir un nuevo pacto educativo en la Argentina y, en especial, una redefinición del vínculo familia-escuela. Para él era perentorio redefinir el marco de solidaridades vigente en la sociedad, que consideraba forzado y artificial, y reemplazarlo por otro en el que primara una solidaridad social buscada racionalmente. Esto era fundamental por la dictadura del dinero y el materialismo reinantes, consecuencia del auge y protagonismo de nuevos inmigrantes, sobre todo en las ciudades. Su diagnóstico era muy específico y llegó a señalar que: «el inmigrante muy meritorio como elemento del trabajo nos ha impuesto su moral del dinero cuyos estragos no hemos sabido prever por inercia nativa y por incultura» (LUGONES, I909C: 40). Era este en parte también responsable del brutal utilitarismo causante del fracaso de la enseñanza.

Para paliar esa situación, una de cuyas manifestaciones más evidentes era «la insolencia despreciativa contra el pobre», proponía Lugones una fuerte interven- 
ción del Estado a través de la escuela. Para lograr los nuevos lazos solidarios y una mayor espiritualidad, propios del nuevo equilibrio no conflictivo que buscaba, sugería dirigir la mirada hacia formas tradicionales de sociabilidad que se estaban perdiendo. Proponía mirar hacia una época dorada, en la que los pobres a los que intentaba reivindicar y legitimar se habían caracterizado, entre otras cosas, por su deferencia. Resulta evidente que el inmigrante en esa mirada austera y espiritual representaba uno de los males de la modernidad.

Tanto en la narrativa de cohesión social impulsada por Bunge como en la de Lugones, la integración social y cultural de los inmigrantes a través de la educación patriótica tenía un correlato en la entronización de las mujeres, otro sector social al que consideraban fundamental en el nuevo pacto solidario que proponían. Sin embargo, y como queda claro en Didáctica de Lugones y de forma bastante más ambigua en Bunge, en un libro publicado pocos años antes, se trataba de un impulso que no requería de una promoción especial del sector. La patria, elemento de cohesión ideológico y simbólico clave, era un sentimiento que debía promoverse en el seno del hogar y dentro de un nuevo pacto hogar-escuela. Para ello era contraproducente desviar la atención hacia estrategias de coeducación y promoción de la mujer que más bien tendían a debilitar con equívocas racionalidades competitivas su papel social fundamental (BUNGE, I904; LUGONES, I909; OSTROvSKY, 20IO).

Estos discursos convivieron con otros que, preocupados por las derivas de la sociabilidad y la cultura argentinas, resaltaban aspectos diferentes. La opinión de funcionarios educativos, que eran también en muchos casos notables intelectuales, destaca no solo por su interpretación global del proceso de imposición de la educación patriótica sino sobre todo por sus sintomáticas dudas. ¿Qué opinaban y cómo actuaban aquellos sobre quienes recaía la responsabilidad de aplicar y hacer llegar hasta la misma base del sistema educativo las propuestas oficiales de impulsar ese tipo de educación en las escuelas públicas? Una inmersión por esos espacios nos muestra una pluralidad de opiniones que permite reconocer la existencia de un clima de tensión productiva muy importante en el que aquellos funcionarios/ intelectuales ejercieron un papel clave.

En 1908, Pablo Pizzurno, como funcionario docente de más alto rango, fue el encargado de gestionar el mandato patriótico de Ramos Mejía. Una vez recibida la directiva de organizar un plan sistemático, elaboró una minuciosa circular en la que dejó sentada su posición. Esta debe ser leída entrelíneas, debido a que habían ya trascendido las diferencias que mantenía con el máximo responsable 
político del área. Pizzurno compartía la preocupación vigente con respecto a los resultados complejos del proceso de inmigración masiva. Encontraba problemas en la sociedad argentina dadas «las escasas condiciones para fundir en un molde tradicional que no existe al extranjero que incesantemente nos invade» (PIZzURNO, 1908: 230). También se mostraba de acuerdo con la necesidad de reaccionar resueltamente contra el "ambiente de indiferentismo que nos rodea» y en que interesaba «retemplar la fibra patriótica». Sin embargo, su convicción de que la escuela era resultado del ambiente y que el maestro debía ser el eje de toda política educativa le permitió mantener una mirada sobre el proceso de cohesión social que la educación patriótica impulsaba más empática que la de otros colegas. Mostró una calculada distancia con respecto a la imposición de un tipo de patriotismo que consideraba excluyente. Sus informes destacaron en varias ocasiones la necesidad de inculcar al niño «el respeto a todas las nacionalidades», «el amor a todos los hombres» y generar en él una mayor conciencia de los deberes del ciudadano, algo más amplio que la difusión superficial y esporádica de rituales patrióticos.

En el momento en que se dieron a conocer las primeras medidas en pro de la educación patriótica comenzaron a escucharse opiniones de docentes que interpretaban de una manera particular su sentido y objetivos. En Paraná, Casimiro Olmos, abogado y profesor de historia y geografía egresado de la Escuela Normal de dicha ciudad, destacaba ante profesores y alumnos la urgencia con que según su criterio debía impulsarse la educación patriótica. En esto se mostraba en sintonía con el tono de las recomendaciones oficiales, y sin embargo para él el problema no era tanto el cosmopolitismo sino una cuestión mayor que lo subsumía: «el indiferentismo que nos ahoga» (olmos, 1908: 80).

Culpaba de la situación a la escuela que no estaba a la altura de su misión de contribuir a formar el «alma nacional». Responsabilizaba de esto a las autoridades por haber entregado la formación patriótica a la historia, sin atender al hecho de que patriotismo y civismo eran en realidad sinónimos. Comentaba que «al concepto de patria no se llega con lecciones áridas de historia sino con lecciones prácticas de moral» para agregar que «será inútil que tendamos ante su vista (la de los niños) los ejemplos de los hechos gloriosos, no los haremos patriotas» (olmos, 1908: 83). El hecho de haber optado por el camino erróneo resultó en una falta alarmante de espíritu cívico entre la población y la proliferación de un patriotismo vacío, que en vez de resaltar los elementos verdaderamente cohesionadores optaba por el espectáculo. Reclamaba como solución un nuevo pacto educativo orientado a 
redefinir los vínculos entre escuela, familia y medio ambiente. Este último presentaba problemas, sobre todo por los vicios y falta de capacidad observados en el gobierno y en el sistema político, que colocaban al docente y a la escuela frente a una compleja disyuntiva. Debían formar alumnos que pudieran adaptarse al medio social y político y no virtuosos encapsulados que a los primeros choques se pasaran al terreno de la desilusión o la rebeldía. Proponía como alternativa el impulso de un patriotismo cívico eficaz, intermedio entre un cosmopolitismo sin bandera y otro tan práctico «que anula el carácter moral y los sentimientos de fraternidad erigiendo al dólar en Dios» (olmos, 1908: 91).

El inspector técnico José J. Berrutti, reconocido por su papel en las Conferencias Pedagógicas organizadas por el Consejo en la Capital, fijó su posición en una conferencia que impartió en la escuela Presidente Roca (BERRUTtI, 2008: 53I-539). Consideraba allí que la tarea educativa fundamental era cohesionar a la sociedad a través de la lucha contra los vicios sociales y morales que la afectaban. Entre ellos situaba al alcoholismo, la simulación y algunos efectos del colectivismo. Con Bunge coincidió en que el papel más importante de la escuela radicaba en la promoción de sentimientos que facilitaran la unión y confraternidad entre el alumnado y la sociedad. Sin embargo, para él estos no debían ser estrechos sino amplios y sobre todo morales. A diferencia de ciertos intelectuales de la elite que promocionaban una solidaridad intergeneracional y otra entre los «muertos ilustres y los vivos», con un afán indisimuladamente jerárquico, Berruti, tal vez por su experiencia como inspector, priorizó otros derroteros. Estos pueden intuirse por sus frecuentes citas a la pedagogía de Fröebel. Para él, el aporte educativo de la hora a los dilemas que aquejaban a la sociedad radicaba en establecer nuevos vínculos solidarios a partir del impulso a una escuela nueva, la emulación de iniciativas sobre el autogobierno estudiantil y la «redención del niño» (BERRUTTI, I908: 538-539).

En una conferencia titulada «Enseñanza patriótica», impartida en la Escuela Superior $n^{\circ} 3$ del Consejo Escolar $3^{\circ}$ de la Capital, la profesora Rita Latallada puso mucho énfasis en explicar lo que consideraba el sentido político trascendental de esa forma de educación. De hecho, la palabra política es la que con más frecuencia se repite en su exposición. Para ella se trataba de una cuestión imprescindible debido sobre todo al «cosmopolitismo absorbente de nuestras grandes ciudades» (LATAllada, 1909: 304-313). Egresada de la Escuela Nacional de Paraná, se desempeñaba como directora de escuela y era una propagandista eficaz de los métodos y saberes normalistas. A través de citas frecuentes extraídas de Comte, Spencer 
y Herbart, resaltó cómo, para alcanzar un grado deseable de cohesión en la sociedad, "hacer la amalgama, la verdadera unidad de compuestos heterogéneos», era necesario el desarrollo de un «elemento anímico de primer orden». Para su consolidación elaboró un catálogo de siete nociones imprescindibles para dar con el tono preciso de una verdadera enseñanza nacional. Latallada, quien durante la primera parte de su alocución dedicó varios párrafos a describir la complejidad y contradicciones de la posición de mujer y de mujer docente y, por tanto, en cierto sentido deplacé, colocó como cuestión prioritaria en dicho catálogo la noción de igualdad civil y política, tras ella la de libertad, y en tercer lugar la promoción de un marco de moral cívica. Recién en el sexto y séptimo lugar situó cuestiones vinculadas a la promoción de sentimientos patrióticos específicos: «Asimilación por las nuevas generaciones de todo aquello que signifique un elemento orgánico de la nacionalidad» y el «Culto a los héroes». Las colocó justo después de las nociones de tolerancia religiosa y política y del «hábito de la sinceridad, de la verdad, y de la honradez» tanto en el espacio público como privado. Consideraba a este último como un apartado importante para sus objetivos, por lo que creyó necesario aclarar: «Entiéndase bien; hablamos de hábitos no de ideas, es decir que colocamos el problema de la enseñanza patriótica sobre la base del problema de la formación del ser moral que la compenetra y la identifica» (LATALLADA, I909: 309).

Las opiniones sobre el impulso a la educación patriótica que acabamos de mencionar compartían una visión bastante similar arraigada en una ideología con mucha fuerza en el campo docente. Es evidente, especialmente en el caso de aquellos que apostaban por una visión más social de la educación, una cierta incomodidad que se muestra con frecuencia entre líneas durante esos años. Obviamente, no estaban solos: convivían con otro grupo de funcionarios que, con un discurso muy estridente, ocupaba un importante espacio. Entre ellos, resaltó la figura de Ernesto Bavío, quien contaba con el apoyo de Ramos Mejía, que, si bien provenía del mismo tronco normalista, mostró una deriva distinta de la de colegas como Pizzurno, a quien reemplazó en el cargo. Abogó Bavío por iniciativas más homogeneizadoras y en sus informes, sobre todo en su época de inspector de colonias agrícolas, apeló al uso de tópicos que se convertirían en lugares comunes décadas después, como «espíritu antiargentino»o «ausencia de espíritu nacional», con los que se refería a la situación de las escuelas impulsadas por colectividades de inmigrantes (BAVÍO, 1908: 597-605; 1909: 674; NISMAN, 1909: 324). Fue clara su adhesión, a tono con los escritos póstumos de Ramos Mejía, a una visión esencia- 
lista de la Nación y a priorizar los rasgos jerárquicos del vínculo social. Encontraba en el dispositivo militar características que eran dignas de ser imitadas por otros espacios sociales, entre ellos, el educativo.

Otros funcionarios abogaron, en cambio, por fusionar varias de las interpretaciones vigentes sobre el sentido cohesionador y los tiempos de la educación patriótica. Ernesto León O'Dena, abogado correntino y vicedirector de la Escuela de Comercio (Sud) de la Capital, fue notable en varios aspectos. El Monitor lo consideraba «no por cierto un desconocido en nuestras esferas pedagógicas por sus serios y complejos estudios» (O'DENA, I909: 469-500). Destacó también la relevancia de las conferencias que impartiera en 1906 con apoyo oficial sobre distintos tópicos de la enseñanza, como historia, idioma castellano, moral cívica, entre otros, en el marco del impulso a la educación patriótica que se formalizaría poco tiempo después. Según sus propias palabras, se sumó en forma ferviente e inmediata a la iniciativa patriótica de Ramos Mejía, que decía compartir. Sin embargo, adhería solo a algunas de las premisas que sustentaban tales iniciativas. No creía que el tema fuera acuciante aunque sí destacaba su importancia. Consideraba que la cohesión social, en términos de fusión natural y espiritual de las razas, no se daba por la propaganda «sino por obra de la previsora naturaleza». Expresaba que «las razas inmigrantes traen una herencia milenaria de cultura moral, hábitos de trabajo y de economía, amor a la familia, al orden, por lo que es justo apreciar en todo su valor el precioso contingente que traen a nuestro pueblo». Como consecuencia, creía que los recelos contra la inmigración implicaban conspirar contra el porvenir del pueblo argentino (O'DENA, I909: 488-489).

A diferencia de otros intelectuales, O’Dena persistía en un ideal de progreso que abarcaba casi todos los campos. Estaba convencido de que la Argentina, como parte de la comunidad europea civilizada, estaba llamada a desarrollar en la región una cultura superior que la llevaría a ejercer un papel de dirección y equilibrio en el mundo. Es en este punto de su esquema donde interviene la educación patriótica o nacionalista. El reforzamiento de la cohesión implícito en el impulso a tal tipo de educación no se situaba para él en el presente, próspero y armónico, a pesar de ciertos sobresaltos cívicos, sino en el futuro. Tanto la escuela como las instituciones de propaganda social debían poner el máximo celo en garantizar la estabilidad futura, base de toda prosperidad. Dada su creencia en que el destino del hombre era social y colectivo, consideraba que se debían fomentar los lazos de solidaridad y reforzarse al máximo los mecanismos de cooperación social. La 
estrategia pasaba para él por una tarea nacionalista de fomento de los sentimientos colectivos. Esta mirada atenta a una especie de destino manifiesto del país tuvo su contrapartida en la de una serie de inspectores, como Raúl B. Díaz, que por su trabajo se vieron obligados a recorrer todo el país. Las situaciones de precariedad que observaron los llevaron a elaborar una visión más pragmática y aferrada a los problemas concretos que se presentaban en el día a día de la construcción educativa estatal y a destacar otros actores, problemas, y plantear soluciones más descentradas para el fomento de una educación patriótica (FIORUCCI, 20I8).

\section{CONCLUSIONES}

El recorrido histórico que hemos realizado muestra que el impulso a la educación patriótica coordinado por José Ramos Mejía se dio en una coyuntura que, como pocas, implicó serias reflexiones sobre el sentido del vínculo social en Argentina. No se trató de un proceso radical. Más bien apuntó a cierta renovación curricular y, sobre todo, a afianzar aspectos ceremoniales y simbólicos, ya presentes a distinta escala en la educación pública desde tiempo atrás. Estuvo lejos de ser el proyecto de ingeniería positivista minuciosamente concebido que imaginan algunas investigaciones. Tampoco fue un mero intento coyuntural fallido, sino el resultado de una serie de iniciativas de compleja coordinación que, encarnada en actores concretos, implicó arreglos corporativos y diferencias ideológicas. Se trató, en consecuencia, de un experimento que remite al cruce, e incluso a los choques, entre distintas maneras de concebir la acción social y cultural, inducidos por la cristalización de narrativas de largo plazo vinculadas a la educación como eje cohesionador. No es casual en ese sentido que el gran emprendedor de la reforma social de comienzos de siglo J.V. González se mostrara al mismo tiempo $\tan$ involucrado en cuestiones educativas.

Lo más llamativo de este proceso fue que, bajo el paraguas de la educación patriótica, casi todos sus participantes, desde los intelectuales más destacados hasta directoras de escuelas y maestros, consideraban de distinta manera la necesidad perentoria de alcanzar un nuevo pacto de solidaridad que ayudara a redefinir los vínculos sociales existentes. Nuevo pacto solidario que implicaba, como bien lo expresó uno de los participantes, una redefinición de la triple relación entre el hogar, la escuela y el medio ambiente sociopolítico. 
La premura con que desde ámbitos oficiales se instaba a afianzar la educación patriótica debió hacer frente a dudas y a distintas interpretaciones sobre las formas prioritarias de promover la cohesión social. Así, por ejemplo, al lado de Ernesto Bavío, quien abogaba por afianzar un tipo de educación a partir de una idea de Nación de tintes esencialistas, Rita Lattallada, colocaba como prioridad de la educación patriótica la promoción de una igualdad cívica. José Berrutti la hacía depender de la consolidación de una nueva escuela y de la redefinición del niño como actor social, y Ernesto León O’Dena situaba su importancia no tanto en el presente, que consideraba ampliamente satisfactorio, sino en el futuro, como reaseguro del cumplimiento de las expectativas de grandeza del país. Resulta evidente que los matices mencionados en su aplicación convirtieron a las urgentes propuestas oficiales, derivadas de una visión pesimista sobre la composición social del país aunque no con respecto a sus posibilidades futuras, en una cuestión compleja y sujeta a múltiples negociaciones.

Conviene, por último, recordar aquí que la elite educativa, básicamente de tradición normalista, funcionó como una elite intelectual subordinada. La consecuencia más evidente de tal subordinación fue que políticos y otros profesionales, en particular médicos como Ramos Mejía o Arata, ocuparon en general los cargos oficiales más relevantes. Sin embargo, el dinamismo, control sobre espacios intermedios y capacidad tanto para reformular las indicaciones recibidas como para generar iniciativas propias, de figuras como Pizzurno, Latallada, Díaz, y el propio Lugones, indican que es erróneo identificar subordinación con mera debilidad. A modo de conclusión, pero con el afán de seguir debatiendo sobre un tema que consideramos muy abierto, podemos afirmar que los rasgos más notorios de esa situación de subordinación, entendida como un complejo entramado de acciones y reacciones jurisdiccionales, ideológicas e incluso políticas y de género, incidieron de manera decisiva en la trayectoria efectivamente seguida por la misión encomendada a Ramos Mejía de cohesionar a la población y homogenizarla culturalmente a través de intensificar la educación patriótica en las escuelas. Tuvieron, en consecuencia, un importante papel en las reflexiones sobre el vínculo social en una década clave de la historia argentina. 


\section{Referencias bibliográficas}

ACRI, MARTín (2012): Las asociaciones y gremios docentes de la Argentina. La situación laboral, la organización y las primeras luchas (1881-1930), Tesis de Maestría, Facultad Latinoamericana de Ciencias Sociales, Sede Buenos Aires.

ALLIAUD, ANDREA (2007): Los maestros y su historia. Los orígenes del magisterio argentino, Buenos Aires, Granica.

BARBA SOLANO, CARLOS Y COHEN, NESTOR (COORDS.) (2011): Perpectivas Críticas sobre la cohesión social, Buenos Aires, Consejo Latinoamericano de Ciencias Sociales.

BAVÍO, ERNESTO (1908): «Las escuelas extranjeras en Entre Ríos. Un problema de alta política nacional», en: El Monitor de la Educación Común, 51, XXVIII, pp. 597-605.

BAVÍ0, ERNESTO (1909): "La escuela y la patria», en El Monitor de la Educación Común, n 438 , vol. XXVIII, p. 674.

BERRUTTI, JOSÉ (1908): «Niños, padres y maestros (conferencia dada en la escuela Presidente Roca», en: El Monitor de la Educación Común, 430, XVIII, pp. 531-539.

BERTONI, LILIA ANA (2001): Patriotas, cosmopolitas y nacionalistas. La construcción de la nacionalidad argentina a fines del sig/o XIX, Buenos Aires, Fondo de Cultura Económica.

BOHOSLAVSKY, ERNESTO Y SOPRANO, GERMÁN (2010): Un estado con rostro humano, Buenos Aires, Prometeo.

BOTANA, NATALIO (1984): La tradición republicana, Buenos Aires, Editorial Sudamericana.

BOTANA, NATALIO Y GALLO, EZEQUIEL (1997): De la república posible a la república verdadera (1880-1910), Buenos Aires, Ariel.

BRYCE, BENJAMIN Y SHEININ, DAVID M.K. (2017): Making Citizens in Argentina, Pitsburgh Pa, University of Pitsburgh Press.
BUNGE, CARLOS OCTAVIO (1904): Educación de la mujer, Buenos Aires, Imprenta y Casa Editora de Coni Hermanos.

BUNGE, CARLOS OCTAVIO (1905): Nuestra América (Ensayo de psicología social), Buenos Aires, Valerio Abeledo editor.

BUNGE, CARLOS OCTAVIO (1908a): "La educación patriótica ante la Sociología, en: El Monitor de la Educación Común, nº 42, vol. XXVIII, pp. 67-70. BUNGE, CARLOS OCTAVIO (1908b): «Bosquejo histórico de la enseñanza nacional», en: El Monitor de la Educación Común, n 44, vol. XXVIII, pp. 436-461. CARLI, SANDRA (2005): Niñez, pedagogía y política. Transformaciones de los discursos acerca de la infancia en la historia de la educación argentina entre 1880 y 1955, Buenos Aires, Facultad de Filosofía y Letras.

CIAFFARDO, CARLOS (1991): «Sobre la educación patriótica. Algunos comentarios acerca de «El fracaso del proyecto argentino», en: Anuario IEHS, vol. VI, pp. 351-360.

CRIADO, ENRIQUE MARTín (2010): La escuela sin funciones, Barcelona, Editorial Bellaterra.

DELANEY, JEANE, (1997): «National Identity, Nationhood and Inmigration in Argentina: 1810-1930", Stanford Electronic Humanities Review, n ${ }^{\circ} 5$, vol. 2.

DE SWAAN, ABRAM (1992): A cargo del Estado, Barcelona, Pomares-Corredor.

DEVOTO, FERNANDO (2002): Nacionalismo, fascismo

y tradicionalismo en la Argentina moderna. Una historia, Buenos Aires, Siglo XXI de Argentina Editores.

DEVOTO, FERNANDO (2003): Historia de la inmigración a la Argentina, Buenos Aires, Sudamericana.

DONZELOT, JACQUES (2007): La invención de lo social. Ensayo sobre la declinación de las pasiones políticas: Buenos Aires, Editorial Nueva Visión. 
DUARTE, DANIEL (1992): «Origen y función del Monitor de la Educación Común. Una herramienta fundamental para la tarea educativa (1881-1888)», en: Páginas, nº 6, vol. 10, pp. 129-149.

DURKHEIM, EMILE, (2004 [1893]): La división del trabajo social, Buenos Aires, Ediciones Libertador. DUSSEL, INÉS (1995): «Pedagogía y burocracia. Notas sobre la historia de los inspectores", en: Revista Argentina de Educación, n 13 , vol. 23, pp. 55-81. ECHEVERRÍA, OLGA, (2010): «Nación y nacionalismo en el origen de la derecha argentina. Leopoldo Lugones y Carlos Ibarguren» en Cuadernos Americanos, n 3, vol. 133, Madrid, pp. 11-41.

ESCUDÉ, CARLOS (1990): El fracaso argentino, Buenos Aires, Editorial Tesis, 1990.

FINOCCHIO, SILVIA (2009): La escuela en la historia argentina, Buenos Aires, EDHASA.

FINOCCHIO, SILVIA (2013): «El papel de la educación en la invención de lo social», en:Revista de Indias, no 73, vol. 257, pp. 219-238.

FIORUCCI, FLAVIA (2004): «La fundación de escuelas normales en Argentina (1890-1930)», en: Revista Mexicana de Historia de la Educación, II, 3, pp. 25-45.

FIORUCCI, FLAVIA (2016): «País afeminado, proletariado feminista, mujeres inmorales e incapaces: la feminización del magisterio en disputa, 19001920», en: Historia de la Educación. Anuario, nº 17, vol. 2, pp. 120-137.

FIORUCCI, FLAVIA (2018): «Raúl B. Díaz: inspector e intelectual de Estado», en: Rodríguez, Laura Graciela y Soprano, Germán (comps.), Profesionales e intelectuales de Estado. Análisis de perfiles y trayectorias en la salud pública, la educación y las fuerzas armadas, Rosario, Prohistoria Ediciones, pp. 141-160.

FANLO, LUIS (2007): «Sociología positivista y educación patriótica en el discurso de Carlos Octavio Bunge», en: Sociedad, 26, pp. 211-231.
GAGLIANO, RAFAEL S. (1991): «Nacionalismo, inmigración y pluralismo cultural. Polémicas educativas en torno al Centenario», en: Adriana Puigross (dir.), Sociedad civil y Estado en los orígenes del sistema educativo argentino, Buenos Aires, Editorial Galerna, pp. 281-309.

GELLNER, ERNEST (1998): Naciones y nacionalismo, Madrid, Alianza Editorial, 1988.

GONZÁLEZ BERNALDO, PILAR (2018): «Sociabilidad y regímenes de lo social en sociedades post imperiales: una aproximación al largo siglo XIX argentino», en: Santiago Castillo Alonso (comp.) La sociabilidad en la historia, Madrid, Catarata. GONZÁLEZ LEANDRI, RICARDO (2001): "La élite profesional docente como fracción intelectual subordinada. Argentina: 1852-1900», Anuario de Estudios Americanos, $\mathrm{n}^{\circ}$ 2, vol. LVIII, pp. 513-535.

GONZÁLEZ LEANDRI, RICARDO; GONZÁLEZ BERNALDO DE QUIRÓS, PILAR Y GALERA GÓMEZ, ANDRÉS (COORDS.) (2016): Regulación social, regímenes de bienestar y Estado en América latina: del liberalismo al neo-liberalismo (siglos XIX-XXI). Circulación de saberes, actores e instituciones, Madrid, Polifemo.

GORELIK, ADRIÁN (2001): La grilla y el parque. Espacio público y cultura urbana en Buenos Aires, 1887-1936, Bernal, Universidad Nacional de Quilmes.

HALPERIN DONGHI, TULIO (1980): Proyecto y construcción de una nación, Caracas, Biblioteca Ayacucho.

HALPERIN DONGHI, TULIO (2003): « ¿Para que la inmigración? Ideología y política inmigratoria en la Argentina (1810-1914)», en Halperín Donghi, Tulio, El espejo de la historia, Buenos Aires, Sudamericana, pp. 87-93.

MARENGO, ROBERTO (1991): «Estructuración y consolidación del poder normalizador: el Consejo 
Nacional de Educación», en: Adriana Puigross (comp.), Sociedad Civil y Estado en los orígenes del sistema educativo argentino, Galerna, Buenos Aires, pp. 71-176.

LATALLADA, RITA (1909): «Enseñanza patriótica», en: El Monitor de la Educación Común, 436, XXVIII, pp. 304-313

LEGARRALDE, MARTíN (2008): La formación de la burocracia educativa en Argentina: Ios inspectores nacionales y el proceso de escolarización, 1871-1910, Tesis de Maestría, Facultad Latinoamericana de Ciencias Sociales Sede Buenos Aires. LIONETTI, LUCÍA (2007): La misión política de la escuela pública. La formación de los ciudadanos en Argentina, 1870-1916, Buenos Aires, Editorial Miño y Dávila.

LUGONES, LEOPOLDO (1908): «Didáctica. La escuela», en: El Monitor de la Educación Común, ${ }^{\circ}$ 431, vol. XXVIII, noviembre 30, Buenos Aires, pp. 589-597.

LUGONES, LEOPOLDO (1909a): "Didáctica. Personal docente», en: El Monitor de la Educación Común, $n^{\circ}$ 434, vol. XXVIII, pp. 216-233.

LUGONES, LEOPOLDO (1909b): «Didáctica. El alumno ante la escuela», en: El Monitor de la Educación Común, n 436, vol. XXVIII, pp. 36-49.

LUGONES, LEOPOLDO (1909c): «Didáctica. El alumno en la escuela», en: El Monitor de la Educación Común, n 438, vol. XXVIII, pp. 417-445.

MORGADE, GRACIELA (COMP.) (1992): Mujeres en la educación. Género y docencia en Argentina 1870-1930, Buenos Aires, Miño y Dávila Editores.

MÜLLER, DETLEF K.; RINGER, FRITZ Y SIMON, BRIAN (COMPS.) (1992): El desarrollo del sistema educativo moderno. Cambio estructural y reproducción social 1870-1920, Madrid, Ministerio de Trabajo y Seguridad Social.

NISMAN, JUAN (1909): «El cosmopolitismo, la educa- ción y el estado», en: El Monitor de la Educación Común, no 433, vol. XXVIII, pp. 3-24.

O'DENA, ERNESTO LEÓN (1909): «Apuntes para un libro de moral cívica», en: El Monitor de la Educación Común, n 438, vol. XXVIII, pp. 469-500. OLMOS, CASIMIRO (1908): «Educación Patriótica (conferencia dada a los maestros primarios de Paraná)», en: El Monitor de la Educación Común, no 428, vol. XXVIII, pp. 80-94.

OSTROVSKY, ANA ELISA (2010): «Carlos Octavio Bunge y el feminismo", en: /l Congreso Internacional de Investigación y Práctica Profesional en Psicología XVII, Mercosur, Facultad de Psicología, Buenos Aires, Universidad de Buenos Aires.

PINEAU, PABLO (1997): La escolarización de la provincia de Buenos Aires (1875-1930). Una visión posible, Buenos Aires, Facultad Latinoamericana de Ciencias Sociales.

PIZZURNO, PABLO (1908): «La educación patriótica. Informe del inspector técnico general», en: $E l$ Monitor de la Educación Común, n 425, vol. XXVIII,Buenos Aires, pp. 230-245.

RAMOS MEJÍA, JOSÉ MARÍA (1904): Los simuladores del talento en las luchas por la personalidad y la vida, Barcelona, F. Granada y Cía.

RAMOS MEJÍA, JOSÉ MARÍA (1952 [1899]): Las multitudes argentinas, Buenos Aires, Guillermo Kraft. RODRÍGUEZ, LAURA GRACIELA Y SOPRANO, GERMÁN (2018): «De las profesiones liberales y los intelectuales contra el Estado, al estudio de los profesionales e intelectuales de Estado», en: Rodríguez Laura Graciela y Soprano, Germán, Profesionales e intelectuales de Estado. Análisis de perfiles y trayectorias en la salud pública, la educación y las fuerzas armadas, Rosario, Prohistoria Ediciones, pp. 9-68.

SARMIENTO, DOMINGO FAUSTINO (1849), Educación Popular: Santiago de Chile, Imprenta de Julio Belín y Compañía. 
SOLBERG, CARL (1970): Inmigration and Nationalism, Argentina and Chile, 1890-1914, Austin, University of Texas Press.

SZUCHMAN, MARK, (1988): Order, Family and Community in Buenos Aires 1810-1860, Stanford, Stanford University Press.

SURIANO, JUAN (2000): La cuestión social en Argentina, Buenos Aires, La Colmena.

TEDESCO, JUAN CARLOS (1986): Educación y Sociedad, Buenos Aires, Solar.

TERÁN, OSCAR (2000), Vida intelectual en el Buenos Aires fin-de siglo (1880-1910,) Buenos Aires, Fondo de Cultura Económica.
TIRONI, EUGENIO Y SORJ, BERNARDO (2007): «Cohesión social. Una visión desde América Latina», en: Pensamiento Iberoamericano, $\mathrm{n}^{\circ}$ 1, pp. 105-127. YANNOULAS, SILVIA CRISTINA (1993): «Educar: ¿una profesión de mujeres? La feminización del Normalismo y la Docencia en Brasil y Argentina 1870-1930", en: Revista Brasileira de Estudos Pedagógicos, vol. 74, n 178, pp. 713-738. ZIMMERMAN, EDUARDO (1994): Los liberales reformistas, Buenos Aires, Sudamericana. 